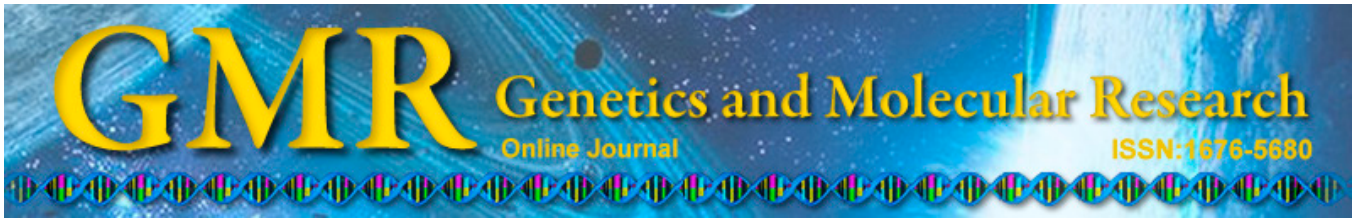

\title{
Serum immunoglobulin E level and its impact on the pregnancy outcome associated with fetal growth restriction: a prospective cohort study
}

\author{
F. Xiong ${ }^{1,2}$, Y. Tong ${ }^{2,3}$, P. $\mathrm{Li}^{2,3}$, T. Huo ${ }^{2,3}$ and M. Mao ${ }^{2,3}$ \\ ${ }^{1}$ Department of Pediatrics, West China Second University Hospital, \\ Sichuan University, China \\ ${ }^{2}$ Laboratory of Early Developmental and Injuries, \\ West China Institute of Woman and Children's Health, \\ West China Second University Hospital, Sichuan University, China \\ ${ }^{3}$ Key Laboratory of Obstetric \& Gynecologic and Pediatric Diseases and Birth \\ Defects of Ministry of Education, Sichuan, China \\ Corresponding author: M. Mao \\ E-mail: dffmmao@126.com
}

Genet. Mol. Res. 14 (2): 3879-3888 (2015)

Received February 21, 2014

Accepted January 19, 2015

Published April 27, 2015

DOI http://dx.doi.org/10.4238/2015.April.27.2

\begin{abstract}
We evaluated the relationship between total serum immunoglobulin $\mathrm{E}$ ( $\mathrm{IgE}$ ) levels and pregnancy outcome in a prospective cohort study focusing on fetal growth restriction (FGR). Sixty women with FGR and twenty with normal singleton pregnancy were enrolled during their third trimester. Infants were followed up for 6 months. Blood samples were obtained from pregnant women during the third trimester; cord blood samples were also taken. Six months after birth, blood samples were obtained from infants. Demographic and baseline characteristics were compared between groups. Birth weight, length and head circumference of neonates in the FGR group were lower than those in the control group. Total serum IgE level was significantly
\end{abstract}


increased in third-trimester pregnant women with FGR compared with normal group $(\mathrm{P}<0.05)$. However, this trend was not observed in the cord blood at birth or peripheral blood of 6-month-old infants. The prevalence of atopic eczema between the 2 groups was similar. Linear regression analysis revealed that the IgE level in the third trimester was negatively correlated with birth weight $(\mathrm{P}<0.05)$. Higher serum $\operatorname{IgE}$ level in the cord blood was significantly associated with an increased risk of being small for gestational age $(\mathrm{P}<0.05)$. In conclusion, $\operatorname{IgE}$ levels in the third trimester of pregnancy and cord blood are strongly related to birth outcomes of FGR.

Key words: Cohort study; Fetal growth restriction; Immunoglobulin E

\section{INTRODUCTION}

There is increasing support of Barker's "programming" hypothesis, which states that an early prenatal and postnatal environment can affect permanent or long-term outcomes regarding the structure or function of different organ systems in the fetus. It has been demonstrated that an adverse intrauterine environment may increase the risk of cardiovascular and metabolic diseases later in life (Barker, 1992; Gillman, 2005; Gluckman et al., 2010). Studies have indicated that human immune function may in part be programmed by early experiences, particularly in the in utero environment (Rowe et al., 2007; Mold et al., 2008).

Fetal growth restriction (FGR) is a clinical syndrome. FGR may induce immunological abnormalities, resulting in partial rejection of the fetal allograft. The intrauterine "programmed" changes may affect the FGR immune system in later life. An allergic reaction of FGR appears to occur in very early life, and likely occurs sometime before birth (Warner et al., 2000). Prenatal maternal-fetal interactions and early-life programming may be associated with the development of asthma or allergic diseases (Ege et al., 2008; Kumar, 2008; Peters et al., 2009). Specific maternal complications as well as maternal stress during pregnancy and delivery may increase the risk of allergy and asthma among offspring later in life. KeskiNisula et al. (2009) found that maternal pre-eclampsia and placental abruption were associated with an increased risk of severe atopy in adolescents. However, few studies have explored the relationship between immunoglobulin E (IgE) and pregnancy complications, and only 1 study carried out more than 20 years ago reported that maternal serum IgE levels were higher in preeclamptic pregnancies (Alanen, 1984).

Laboratory diagnosis for allergy has not been standardized; however, serum concentrations of IgE are generally higher in allergic individuals. Previous studies found that anthropometric parameters at birth were related to serum IgE level and, later, asthma (Hagström et al., 1998; Gregory et al., 1999; Oryszczyn et al., 1999; Brooks et al., 2001; Akinbami and Schoendorf, 2002; CDC, 2002), but the exact physiological mechanisms are unclear. A major clinical consideration is how to determine which patients should be considered "allergic" or "at risk to become allergic". Previous studies examining the relationship between IgE and FGR have been limited to retrospective cross-sectional studies, not a prospective cohort study. The aim of this study was to examine the association between FGR and serum IgE in a prospective cohort study. 


\section{MATERIAL AND METHODS}

\section{Study population}

This prospective study was approved by the Regional and Institutional Committee of Science and Research Ethics of the West China Second University Hospital. Informed written consent was obtained prior to enrollment. Eighty pregnant women were divided into 2 groups: 1) 60 pregnant women with singleton pregnancy diagnosed with FGR in the third trimester of pregnancy, 2) age-, parity-, body mass index (weight/height ${ }^{2}$ )-, and gestational age-matched healthy women with singleton pregnancies comprised the control group $(\mathrm{N}=$ 20). FGR was first defined by a lack of increase in fundal height and abdominal circumference through obstetric examination (below the 10th percentile for gestational age). Second, the fetal abdominal circumference was below the 10th percentile for gestation through ultrasonography according to the parameters for Chinese pregnant women (Kurjak et al., 1980; Hadlock et al., 1983; Chambers et al., 1989; Chauhan et al., 2009). Exclusion criteria included the diagnosis of fetal malformations and the presence of some comorbid disease in the mothers, including infectious diseases, preeclampsia or gestational hypertension, gestational diabetes, and allergy diseases, among others. After diagnosis, the FGR pregnant women had been treated with compound amino acid and danshen root for 10-14 days (Zhao and Mao, 2011). The infants were followed-up until 6 months after delivery.

Birth weight, birth length, and head circumference were recorded at delivery. Birth outcomes were analyzed to identify the results for the FGR and control groups, in which preterm birth was defined as gestation $<37$ weeks and full-term birth as gestation $\geq 37$ weeks and $<42$ weeks; being small for gestational age (SGA) was defined as birth weight below the 10th percentile for each gestational age, and appropriate for gestational age (AGA) was defined as birth weight in the 10th to 90th percentile for each gestational age. Centiles were calculated using China birth weight growth charts. Neonatal complications and atopic eczema were recorded during the same period. Atopic eczema was diagnosed if the child had a history of chronic or chronically relapsing itching dermatitis with typical morphology and distribution (Oranje, 1995).

\section{Blood sampling}

Peripheral blood samples from third-trimester mothers (28-36 weeks) enrolled were collected by vein puncture into non-anticoagulated tubes between 07:00 and 09:00 am. Matched cord blood samples were immediately collected in tubes from the umbilical vein of the placenta via cesarean or vaginal route. When the infants were 6 months old, peripheral blood samples were collected by vein puncture. The non-anticoagulated tubes were centrifuged at room temperature with a relative centrifugal force of $3000 \mathrm{~g}$ for $5 \mathrm{~min}$. Serum aliquots were stored at $-80^{\circ} \mathrm{C}$ until further analysis.

\section{Total IgE enzyme-linked immunosorbent assay}

Serum total $\mathrm{IgE}$ concentration (IU/mL) was determined by enzyme-linked immunosorbent assay (EUROIMMUN AG, Leubeck, Germany). Microtiter plate wells were pre-coated with affinity-purified anti-human IgE, and each sample was added in duplicate 
(100 $\mu \mathrm{L} /$ well). Plates were incubated at room temperature for $30 \mathrm{~min}$ and washed. Affinitypurified anti-human IgE detection antibody (conjugated with horseradish peroxidase) was added and the plates were incubated for 30 min and washed. 3,3',5,5'-Tetramethylbenzidine substrate solution was added to induce color development; the reaction was stopped with stop solution, and absorbance was read at $450 \mathrm{~nm}$ (Model 680, Bio-Rad, Hercules, CA, USA). The concentration of total $\operatorname{IgE}$ in each sample was determined using a logistic standard curve of known concentration. Positive, negative, and control samples of varying concentrations were included with each assay, and between-assay coefficients of variation were less than $10 \%$.

\section{Statistical analyses}

Statistical analysis was performed using the SPSS 16.0 software (Chicago, IL, USA). Data with normal distribution are reported as means \pm standard deviation. Differences between groups were tested by the Student $t$-test. Serum total IgE concentrations were log-transformed to approach normal distribution. Mean concentrations were expressed as geometric means with $95 \%$ confidence intervals (CI). Linear trends of total $\mathrm{IgE}$ concentrations and birth weight, birth length, and birth head circumference were analyzed by Pearson's correlation coefficient. The cut-off IgE level of third-trimester, cord blood, and infant peripheral blood at 6 months were defined by the point $100 \mathrm{IU} / \mathrm{mL}$ (De Amici et al., 2008), $1.0 \mathrm{IU} / \mathrm{mL}$ (Shirakawa et al., 1997), and 7.2 IU/mL (De Amici et al., 2008), respectively. Regression analyses were used to analyze the relationship between IgE and birth outcomes, such as SGA, preterm birth, and prevalence of atopic eczema. Odds ratios (ORs) were determined with 95\%CIs. Statistical significance was set at $95 \%(\mathrm{P}<0.05)$.

\section{RESULTS}

\section{Population characteristics}

Eighty women were enrolled in this study and assigned into either an FGR group or a control group. Characteristics of the study subjects are shown in Table 1. In the FGR group, the delivery rate was $91.67 \%(55 / 60) ; 5$ cases were withdrawn, among which labor was induced in 4 patients for the sake of the mother ( 2 cases) or owing to fetus death ( 2 cases). There were 55 newborns delivered in the FGR group. Forty-five infants were delivered by cesarean section $(81.82 \%)$, while the others were vaginal deliveries $(18.18 \%)$. According to the gestational age and birth weight, $27.3 \%$ of newborns were identified as SGA ( $N=15$, ratio $=15 / 55$, prematurity in 8 cases, full-term in 7 cases $)$, and $72.7 \%$ as AGA $(\mathrm{N}=40$, ratio $=40 / 55$, prematurity in 13 cases, full-term in 27 cases). The incidence of prematurity in the FGR group was $38.2 \%(\mathrm{~N}=21$, ratio $=21 / 55)$. In the control group, 17 cesarean sections $(85 \%)$ and 3 vaginal deliveries $(15 \%)$ were performed. All were full-term AGA. There was a significant difference in the frequency of prematurity and SGA between the 2 groups $\left(\chi^{2}\right.$ $=10.606$ and 8.612, respectively; $\mathrm{P}<0.05$ ). For gestational age at birth, birth weight, birth length, and birth head circumference, a significant difference between the 2 groups was found (Table 2). Peripheral blood of 8 infants at 6 months of age in the FGR group was not collected (Figure 1). 
Table 1. Characteristics of pregnant women enrolled in this cohort study.

\begin{tabular}{|c|c|c|c|c|c|c|}
\hline & \multicolumn{2}{|c|}{ FGR group $(\mathrm{N}=60)$} & \multicolumn{2}{|c|}{ Normal group $(\mathrm{N}=20)$} & \multirow[t]{2}{*}{$t$} & \multirow[t]{2}{*}{$\mathrm{P}$} \\
\hline & Means \pm SD & Range & Means $\pm \mathrm{SD}$ & Range & & \\
\hline Age (years) & $29.80 \pm 4.92$ & $20-41$ & $29.90 \pm 2.83$ & $25-38$ & 0.112 & 0.912 \\
\hline BMI before pregnancy & $20.57 \pm 2.97$ & $15.6-30.4$ & $19.73 \pm 1.54$ & $17.1-22.4$ & 1.635 & 0.107 \\
\hline Gravidity & $1.97 \pm 0.90$ & $1-3$ & $1.75 \pm 0.64$ & $1-3$ & 1.176 & 0.246 \\
\hline Parity & $0.25 \pm 0.44$ & $0-1$ & $0.05 \pm 0.22$ & $0-1$ & 1.959 & 0.054 \\
\hline Enrolled gestational age (day) & $233.80 \pm 13.05$ & $29-36$ & $238.70 \pm 9.02$ & $30-36$ & 1.865 & 0.068 \\
\hline
\end{tabular}

\begin{tabular}{|c|c|c|c|c|c|c|}
\hline & \multicolumn{2}{|c|}{ FGR group $(\mathrm{N}=55)$} & \multicolumn{2}{|c|}{ Normal group $(\mathrm{N}=20)$} & \multirow[t]{2}{*}{$t$} & \multirow[t]{2}{*}{$P$} \\
\hline & Means \pm SD & Range & Means \pm SD & Range & & \\
\hline Gestational age at birth (day) & $233.80 \pm 13.05$ & $217-286$ & $238.70 \pm 9.02$ & $262-286$ & 4.704 & $<0.001$ \\
\hline Birth weight (g) & $2626.27 \pm 597.55$ & $1100-3800$ & $3293.50 \pm 259.73$ & $2950-3720$ & 6.718 & $<0.001$ \\
\hline Birth length (cm) & $47.04 \pm 2.95$ & $39-52$ & $49.70 \pm 1.13$ & $47-52$ & 5.652 & $<0.001$ \\
\hline Birth head circumference $(\mathrm{cm})$ & $31.97 \pm 2.41$ & $22-36$ & $34.15 \pm 0.49$ & $33-35$ & 6.368 & $<0.001$ \\
\hline
\end{tabular}

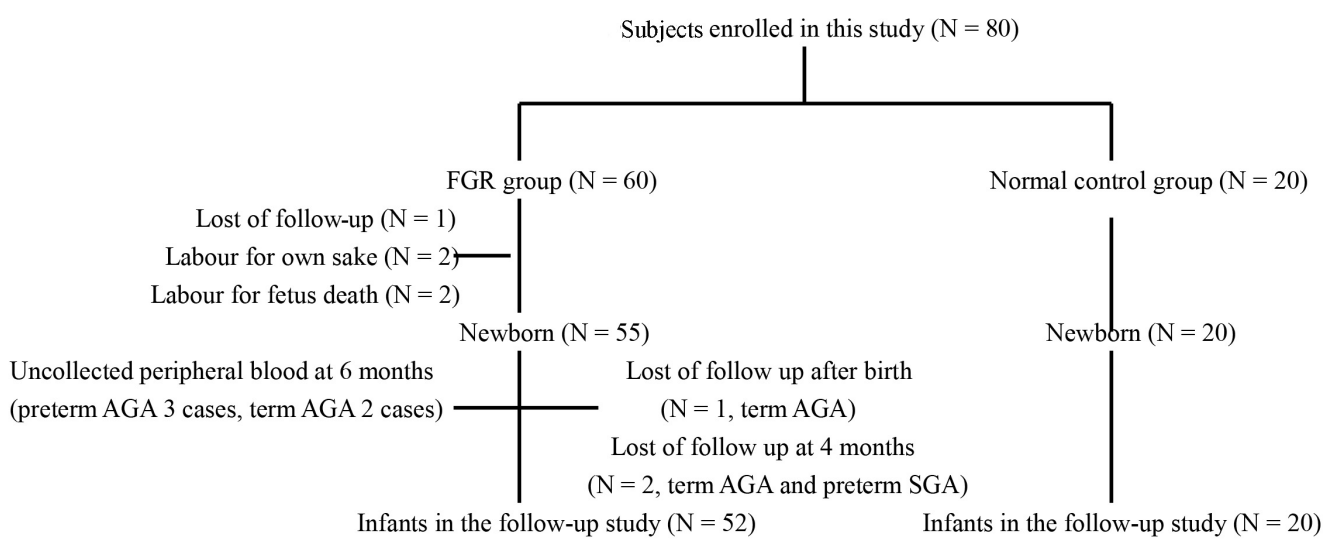

Figure 1. Study follow-up.

The incidence of neonatal complications was $29.09 \%$ in the FGR group, including 14 with neonatal pneumonia, 1 with $\mathrm{ABO}$ hemolytic disease, and 1 with neonatal asphyxia, while these complications were not observed in the control group.

Table 3 shows the differences in total serum IgE levels between the 2 groups at different stages. Total serum IgE level was significantly increased in pregnant women with FGR during third-trimester pregnancy compared with normal pregnant women $(\mathrm{P}<0.05)$, but there were no significant differences between the 2 groups in umbilical cord blood or infants' peripheral blood at 6 months. The prevalence of atopic eczema at 6 months of age did not differ between the 2 groups ( 24.07 vs $35 \%, \mathrm{P}>0.05)$. 
Table 3. Differences in total serum IgE between the 2 groups at different stages.

\begin{tabular}{lccccc}
\hline & & FGR group & Normal group & $\mathrm{Z}$ & $\mathrm{P}$ \\
\hline Third-trimester maternal blood IgE & $\mathrm{N}$ & 60 & 20 & & \\
& $\mathrm{GMs}$ & 38.55 & 11.9 & & $0.046^{*}$ \\
Umbilical cord blood IgE & $95 \% \mathrm{CI}$ & $0.61-525.90$ & $0.1-310.00$ & -1.994 & \\
& $\mathrm{~N}$ & 55 & 20 & & \\
& $\mathrm{GMs}$ & 1.60 & 2.80 & -1.535 & 0.125 \\
Infant peripheral blood at 6 months IgE & $95 \% \mathrm{CI}$ & $0.00-19.88$ & $0.00-73.60$ & & \\
& $\mathrm{~N}$ & 47 & 20 & & \\
& $\mathrm{GMs}$ & 7.4 & 4.75 & -0.713 \\
\hline
\end{tabular}

$* \mathrm{P}<0.05 . \mathrm{FGR}=$ fetal growth restriction; $\mathrm{GMs}=$ geometrical means; $\mathrm{CI}=$ confidence interval.

Linear regression analysis between total serum IgE and birth weight, birth length, and birth head circumference were performed (Table 4). The level of IgE in the third trimester was significantly negatively correlated with birth weight $(\mathrm{P}=0.021)$. Although the differences did not reach statistical significance, there was a negative trend between birth length, birth head circumference, and serum $\operatorname{IgE}$ in the third trimester $(\mathrm{P}=0.066$ and 0.052 , respectively). There were no significant correlations between birth weight, birth length, birth head circumference, and serum IgE in the cord blood.

Table 4. Linear regression analysis of the relationship between birth weight, birth length, birth head circumference, and total serum $\operatorname{IgE}$.

\begin{tabular}{|c|c|c|c|c|c|c|}
\hline & \multicolumn{2}{|l|}{ Birth weight } & \multicolumn{2}{|l|}{ Birth length } & \multicolumn{2}{|c|}{ Birth head circumference } \\
\hline & Regression coefficient & $\mathrm{P}$ & Regression coefficient & $\mathrm{P}$ & Regression coefficient & $P$ \\
\hline Third-trimester maternal blood IgE & -0.31 & $0.021 *$ & -0.25 & 0.066 & -0.264 & 0.052 \\
\hline Umbilical cord blood IgE & 0.183 & 0.212 & 0.106 & 0.473 & 0.152 & 0.302 \\
\hline
\end{tabular}

$* \mathrm{P}<0.05$.

Multiple regression analysis (Table 5) revealed that serum IgE level in umbilical cord blood $(>1.0 \mathrm{IU} / \mathrm{mL})$ remained significantly associated with an increased risk of SGA $(\mathrm{OR}=$ 6.03, 95\%CI: 1.16-31.37, $\mathrm{P}<0.05)$, but not with an increased risk of preterm birth $(\mathrm{OR}=1.41$, $95 \% \mathrm{CI}: 0.41-4.89, \mathrm{P}>0.05)$ or with the occurrence of eczema (OR $=0.63,95 \% \mathrm{CI}: 0.13-2.99$, $\mathrm{P}>0.05)$. IgE in the third trimester and in the peripheral blood at 6 months was not significantly associated with the occurrence of SGA, preterm birth, and eczema.

Table 5. Prevalence odds ratios for birth outcomes, eczema, and serum IgE at different stages.

\begin{tabular}{|c|c|c|c|c|c|c|c|c|c|c|}
\hline & & \multicolumn{3}{|c|}{ SGA } & \multicolumn{3}{|c|}{ Preterm } & \multicolumn{3}{|c|}{ Eczema } \\
\hline & & Yes & No & $\begin{array}{c}\text { Odds ratio } \\
(95 \% \mathrm{CI})\end{array}$ & Yes & No & $\begin{array}{c}\text { Odds ratio } \\
(95 \% \mathrm{CI})\end{array}$ & Yes & No & $\begin{array}{c}\text { Odds ratio } \\
(95 \% \mathrm{CI})\end{array}$ \\
\hline Third-trimester maternal blood IgE & $\begin{array}{l}<100 \mathrm{IU} / \mathrm{mL} \\
\geq 100 \mathrm{IU} / \mathrm{mL}\end{array}$ & $\begin{array}{r}10 \\
5\end{array}$ & $\begin{array}{l}28 \\
12\end{array}$ & $\begin{array}{c}1.00 \\
0.96 \\
(0.24-3.85)\end{array}$ & $\begin{array}{r}12 \\
9\end{array}$ & $\begin{array}{r}26 \\
8\end{array}$ & $\begin{array}{c}1.00 \\
2.12 \\
(0.61-7.33)\end{array}$ & $\begin{array}{r}10 \\
3\end{array}$ & $\begin{array}{l}27 \\
14\end{array}$ & $\begin{array}{c}1.00 \\
0.36 \\
(0.06-2.17)\end{array}$ \\
\hline Umbilical cord blood IgE & $\begin{array}{l}<1.0 \mathrm{IU} / \mathrm{mL} \\
\geq 1.0 \mathrm{IU} / \mathrm{mL}\end{array}$ & $\begin{array}{r}3 \\
13\end{array}$ & $\begin{array}{l}19 \\
20\end{array}$ & $\begin{array}{c}1.00 \\
6.03^{*} \\
(1.16-31.37)\end{array}$ & $\begin{array}{r}7 \\
13\end{array}$ & $\begin{array}{l}15 \\
20\end{array}$ & $\begin{array}{c}1.00 \\
1.41 \\
(0.41-4.89)\end{array}$ & $\begin{array}{l}8 \\
6\end{array}$ & $\begin{array}{l}13 \\
27\end{array}$ & $\begin{array}{c}1.00 \\
0.63 \\
(0.13-2.99)\end{array}$ \\
\hline Infant peripheral blood at 6 months $\operatorname{IgE}$ & $\begin{array}{l}<12 \mathrm{IU} / \mathrm{mL} \\
\geq 12.0 \mathrm{IU} / \mathrm{mL}\end{array}$ & $\begin{array}{l}7 \\
7\end{array}$ & $\begin{array}{l}18 \\
15\end{array}$ & $\begin{array}{c}1.00 \\
1.20 \\
(0.34-4.20)\end{array}$ & $\begin{array}{l}9 \\
8\end{array}$ & $\begin{array}{l}16 \\
14\end{array}$ & $\begin{array}{c}1.00 \\
1.02 \\
(0.31-3.35)\end{array}$ & $\begin{array}{l}5 \\
7\end{array}$ & $\begin{array}{l}20 \\
15\end{array}$ & $\begin{array}{c}1.00 \\
2.19 \\
(0.46-10.45)\end{array}$ \\
\hline
\end{tabular}

$* \mathrm{P}<0.05$. 


\section{DISCUSSION}

The results of this prospective cohort study on FGR further support that a relationship exists between IgE and fetal growth. The results suggested that IgE is involved in the pathogenesis of FGR. Third trimester IgE and cord blood IgE were strongly related to the birth outcome of FGR, including birth weight, birth length, birth head circumference, and increased risk of SGA.

FGR is a clinical syndrome associated with 2-3 times increased perinatal mortality and morbidity (Thomas et al., 2000; Horbar et al., 2002; Thorp et al., 2002; Garite et al., 2004). Our results showed that the incidence of SGA and premature birth were 27.3 and $38.1 \%$, respectively, whereas all control babies were full-term AGA. Moreover, the incidence of neonatal disease was $29.09 \%$ in the FGR group, including neonatal pneumonia, hemolytic disease in newborns, and asphyxia in newborns. However, no complications were observed in the normal control group. Not all FGR infants are small enough to be diagnosed with SGA, but FGR was affected by the intrauterine environment of malnutrition or other adverse factors at a critical period. The organs undergo adaptability programming that continues throughout life despite the relief of adverse conditions after birth.

Our results showed that the level of total serum IgE was significantly increased in third-trimester pregnant women with FGR compared with that in normal pregnant women, but the difference in IgE level in the cord blood or peripheral blood at month 6 was not statistically significant. The pregnant women enrolled in this study had no atopic disease, although the exact mechanism underlying the association is unclear, and an elevated level of IgE may be involved in the pathogenesis of FGR. Løken et al. (2010) found that pregnant women had elevated total IgE levels compared with nonpregnant subjects. This finding suggests that increased total IgE level during pregnancy is a general immunological response to carrying a fetus. No previous study has reported an association between maternal IgE levels and FGR. IgE has been closely linked to allergic disorders and may play a pivotal role in non-atopic disease (Beeh et al., 2000; Oettgen and Geha, 2001; Milgrom, 2002). The impact of IgE on FGR risk is unknown, but an increased risk of pregnant pre-eclampsia, hypertension, and low birth weight had been observed in patients with asthma (Keski-Nisula et al., 2009). A prospective large sample size is required to demonstrate the relationship between IgE and FGR.

Anthropometric parameters at birth reflect fetal growth and intrauterine nutritional status to some extent. Several studies demonstrated an association between birth weight, birth length, and later asthma (Leadbitter et al., 1999). Many studies have reported that a large head circumference at birth was associated with elevated total $\mathrm{IgE}$ as well as with the development of hay fever and asthma in later life (Gregory et al., 1999; Oryszczyn et al., 1999). In addition, low birth weight was associated with allergic rhinitis and asthma (Hagstrom et al., 1998; Brooks et al., 2001; Akinbami and Schoendorf, 2002; CDC, 2002). Our study found that thirdtrimester maternal serum IgE levels with FGR had a negative relationship with birth length and birth head circumference, but showed a significant relationship with birth weight $(\mathrm{P}=0.021)$. A previous study found that cord blood IgE was significantly higher when maternal $\operatorname{IgE}$ was over $100 \mathrm{IU} / \mathrm{mL}$ (De Amici et al., 2008). We chose the cut-off point for pregnant women serum $\operatorname{IgE}$ as $100 \mathrm{IU} / \mathrm{mL}$, but we found no relationship between third-trimester maternal blood $\operatorname{IgE}$ level and the prevalence of SGA and preterm. A commonly cited cut-off point is cord blood $\operatorname{IgE} 1.0 \mathrm{IU} / \mathrm{mL}$ (Shirakawa et al., 1997). It is thought that IgE antibodies cannot cross into the placenta, although the fetus can synthesize IgE starting at the 11th week of gestation (Shah and 
Bapat, 2006). We found an association between IgE concentration in cord blood and increased risk of SGA birth, but not preterm birth. These results suggest that anthropometric parameters affected by the in utero environment may interact with immunological "imprinting".

Some researchers found that maternal complications as well as prenatal metabolic risk factors may increase the risk of allergy and asthma among offspring later in life. Kumar et al. (2009) reported that term infants of pregnancies with gestational diabetes had a 7.57-fold increased risk of atopic dermatitis and a 5.91-fold increased risk of allergen sensitization. In our study, we found no significant difference in prevalence of eczema at 6 months between FGR and control groups. Although cord serum IgE is a significant risk factor for allergy development in offspring (Shah and Bapat, 2009), the significant association between IgE concentration at different stages and the prevalence of eczema at month 6 was not observed. Significant interest has focused on the possibility of predicting and preventing atopic disorders among children during pregnancy and infancy. Serum total $\operatorname{IgE}$ levels were higher in preadolescent SGA children than in AGA children, although there was no significant difference between the 2 groups in terms of atopy (Bostanci et al., 2008). These findings suggest that both environmental and genetic factors determine the level of serum IgE. It has been hypothesized that when the demand for nutrients later in gestation no longer fully meet the needs of the rapidly growing fetus, the differentiation of specific thymus-derived helper lymphocytes from T-helper 2 type toward T-helper 1 type lymphocytes may be permanently impaired, leading to exaggerated $\mathrm{IgE}$ responses and atopic disease phenomena later in life (Godfrey et al., 1994; Bostanci et al., 2008; Hinz et al., 2010), although some findings are inconsistent. In our study, we found no association between IgE and atopic disease later in life, and the mechanism underlying FGR and atopic disease must be further explored.

In conclusion, our results indicate that compared with normal pregnant women, the level of total serum IgE was significantly increased in third-trimester pregnant women with FGR. In addition, third trimester IgE and cord blood IgE may be strongly related to the birth outcome of FGR. Though there is no evidence supporting a relationship between total serum $\mathrm{IgE}$ at different stages and the prevalence of eczema. As the sample size in this study was small, further large-scale prospective cohort studies are needed to clarify the factors and immunologic mechanisms examined.

\section{ACKNOWLEDGMENTS}

Research supported by the Project of Ministry of Science and Technology of China (\#2009BAT80BD3) and the Project of Provincial Bureau of Health, Sichuan, China (\#110444).

\section{REFERENCES}

Akinbami LJ and Schoendorf KC (2002). Trends in childhood asthma: prevalence, health care utilization, and mortality. Pediatrics 110: 315-322.

Alanen A (1984). Serum IgE and smooth muscle antibodies in pre-eclampsia. Acta Obstet. Gynecol. Scand. 63: 581-582. Barker DJ (1992). The fetal origins of diseases of old age. Eur. J. Clin. Nutr. 46: S3-S9.

Beeh KM, Ksoll M and Buhl R (2000). Elevation of total serum immunoglobulin E is associated with asthma in nonallergic individuals. Eur. Respir. 16: 609-614.

Bostanci I, Dilli D and Dallar Y (2008). Birth size effect on pulmonary functions and atopic sensitization in preadolescence. Pediatr. Int. 50: 648-653.

Brooks AM, Byrd RS, Weitzman M, Auinger P, et al. (2001). Impact of low birth weight on early childhood asthma in the 
United States. Arch. Pediatr. Adolesc. Med. 155: 401-406.

Centers for Disease Control and Prevention (CDC) (2002). Infant mortality and low birth weight among black and white infants - United States, 1980-2000. MMWR Morb. Mortal. Wkly Rep. 51: 589-592.

Chambers SE, Hoskins PR, Haddad NG, Johnstone FD, et al. (1989). A comparison of fetal abdominal circumference measurement and Doppler ultrasound in the prediction of small-for-dates babies and fetal compromise. Br. J. Obstet. Gynaecol. 96: 803-808.

Chauhan SP, Gupta LM, Hendrix NW and Berghella V (2009). Intrauterine growth restriction: comparison of American College of Obstetricians and Gynecologists practice bulletin with other national guidelines. Am. J. Obstet. Gynecol. 200: 409.e1-6.

De Amici M, Belloni C, De Silvestri A, Perotti F, et al. (2008). Immunoglobulin E levels in the 1st year of life. Allergy Asthma Proc. 29: 74-77.

Ege MJ, Herzum I, Buchele G, Krauss-Etschmann S, et al. (2008). Prenatal exposure to a farm environment modifies atopic sensitization at birth. J. Allergy Clin. Immunol. 122: 407-412, e1-4.

Garite TJ, Clark R and Thorp JA (2004). Intrauterine growth restriction increases morbidity and mortality among premature neonates. Am. J. Obstet. Gynecol. 191: 481-487.

Gillman MW (2005). Developmental origins of health and disease. N. Engl. J. Med. 353: 1848-1850.

Gluckman PD, Hanson MA and Mitchell MD (2010). Developmental origins of health and disease: reducing the burden of chronic disease in the next generation. Genome Med. 2: 14.

Godfrey KM, Barker DJP and Osmond C (1994). Disproportionate fetal growth and raised IGE concentration in adult life. Clin. Exp. Allergy 24: 641-648.

Gregory A, Doull I, Pearce N, Cheng S, et al. (1999). The relationship between anthropometric measurements at birth: asthma and atopy in childhood. Clin. Exp. Allergy 29: 330-333.

Hadlock FP, Deter RL, Harrist RB, Roecker E, et al. (1983). A date independent predictor of intrauterine growth retardation: femur length/abdominal circumference ratio. AJR Am. J. Roentgenol. 141: 979-984.

Hagström B, Nyberg P and Nilsson PM (1998). Asthma in adult life-is there an association with birth weight? Scand. J. Prim. Health Care 16: 117-120.

Hinz D, Simon JC, Maier-Simon C, Milkova L, et al. (2010). Reduced maternal regulatory T cell numbers and increased T helper type 2 cytokine production are associated with elevated levels of immunoglobulin E in cord blood. Clin. Exp. Allergy 40: 419-426.

Horbar JD, Badger GJ, Carpenter JH, Fanaroff AA, et al. (2002). Trends in mortality and morbidity for very low birth weight infants, 1991-1999. Pediatrics 110: 143-151.

Keski-Nisula L, Heinonen S, Remes S and Pekkanen J (2009). Pre-eclampsia, placental abruption and increased risk of atopic sensitization in male adolescent offspring. Am. J. Reprod. Immunol. 62: 293-300.

Kumar R (2008). Prenatal factors and the development of asthma. Curr. Opin. Pediatr. 20: 682-687.

Kumar R, Ouyang F, Story RE, Pongracic JA, et al. (2009). Gestational diabetes, atopic dermatitis, and allergen sensitization in early childhood. J. Allergy Clin. Immunol. 5: 1031-1038.e1-4.

Kurjak A, Kirkinen P and Latin V (1980). Biometric and dynamic ultrasound assessment of small-for-dates infants: report of 260 cases. Obstet. Gynecol. 56: 281-284.

Leadbitter P, Pearce N, Cheng S, Sears MR, et al. (1999). Relationship between fetal growth and the development of asthma and atopy in childhood. Thorax 54: 905-910.

Løken MO, Jeansson S, Jenum PA and Eskild A (2010). Serum level of immunoglobulin E during pregnancy - does offspring sex matter? Paediatr. Perinat. Epidemiol. 24: 75-78.

Milgrom H (2002). Attainments in atop: special aspects of allergy and IgE. Adv. Pediatr. 49: 273-297.

Mold JE, Michaelsson J, Burt TD, Muench MO, et al. (2008). Maternal alloantigens promote the development of tolerogenic fetal regulatory T cells in utero. Science 322: 1562-1565.

Oettgen HC and Geha RS (2001). IgE regulation and roles in asthma pathogenesis. J. Allergy Clin. Immunol. 107: 429-440.

Oranje AP (1995). Development of childhood eczema and its classification. Pediatr. Allergy Immunol. 6: 31-35.

Oryszczyn MP, Annesi-Maesano I, Campagna D, Sahuquillo J, et al. (1999). Head circumference at birth and maternal factors related to cord blood total IgE. Clin. Exp. Allergy 29: 334-341.

Peters JL, Suglia SF, Platts-Mills TA, Hosen J, et al. (2009). Relationships among prenatal aeroallergen exposure and maternal and cord blood IgE: project ACCESS. J. Allergy Clin. Immunol. 123: 1041-1046.

Rowe J, Kusel M, Holt BJ, Suriyaarachchi D, et al. (2007). Prenatal versus postnatal sensitization to environmental allergens in a high-risk birth cohort. J. Allergy Clin. Immunol. 119: 1164-1173.

Shah S and Bapat M (2006). Parental history of allergy, maternal serum IgE \& cord serum IgE. Indian J. Med. Sci. 60: 13-18. 
Shah S and Bapat M (2009). Cord serum screening test and the newborns allergic status. Indian Pediatr. 46: 295-299.

Shirakawa T, Morimoto K, Sasaki S, Taniguchi K, et al. (1997). Effect of maternal lifestyle on cord blood IgE factor. Eur. J. Epidemiol. 13: 395-402.

Thomas P, Peabody J, Turnier V and Clark RH (2000). A new look at intrauterine growth and the impact of race altitude and gender. Pediatrics 106: e21.

Thorp JA, Jones PG, Knox E and Clark RH (2002). Does antenatal corticosteroid therapy affect birth weight and head circumference? Obstet. Gynecol. 99: 101-108.

Warner JA, Jones CA, Jones AC and Warner JO (2000). Prenatal origins of allergic disease. J. Allergy Clin. Immunol. 105: S493-S498.

Zhao YM and Mao M (2011). Exploration on Management Software for Early Diagnosis and its Application to Early Diagnosis and Systematic Management of Small for Gestational Age. Doctoral thesis. Sichuan University, 19-21. 